\title{
It's hydrogeology but not as we know it: Sub-seafloor groundwater flow driven by thermal gradients
}

\author{
A. Desens ${ }^{1}$, V.E.A. Post ${ }^{1}$, G.J. Houben ${ }^{1}$, T. Kuhn ${ }^{1}$, M. Walther ${ }^{2,3}$, Thomas Graf ${ }^{4}$ \\ ${ }^{1}$ BGR, Hannover, Germany \\ ${ }^{2}$ Helmholtz-Centre for Environmental Research GmbH - UFZ Leipzig, Department of \\ Environmental Informatics, Leipzig, Germany \\ ${ }^{3}$ Technische Universität Dresden, Professorship of Contaminant Hydrology, Dresden, \\ Germany \\ ${ }^{4}$ Leibniz Universität Hannover, Institute of Fluid Mechanics and Environmental Physics in \\ Civil Engineering, Hannover, Germany
}

\begin{abstract}
Groundwater flow beneath the oceans plays an important role for cooling the earth's crust and geochemical cycles, yet it remains an understudied subject in hydrogeology. This contribution focuses on the circulation of seawater through basalt covered by deep-sea sediments in the equatorial northeast Pacific Ocean. Numerical model simulations are used to infer the factors controlling the flow patterns that develop between basalt outcrops. The energy to drive the flow is derived from the crustal heat flux. It is found that the sediment thickness plays a key role in determining the development of hydrothermal siphons, i.e. the flow between two adjacent seamounts where one acts as a recharge point and the other as a discharge point for seawater. Amongst the various factors tested, the outcrop width was an important factor as well.
\end{abstract}

\section{INTRODUCTION}

It is now firmly established that submarine groundwater discharge plays a major role in the delivery of nutrients and other chemical substances to the ocean. This process has been studied primarily in the near-shore environment (Moore, 2010). Flow processes around midoceanic ridges, evidenced e.g. by "black smokers", have also received a lot of attention. Much less remains known, however, about the role of groundwater flow processes in the deeper oceanic crust between the continents and the mid-oceanic ridges. Large parts of the ocean floor are of this type. In the absence of topographic driving forces, flow here is driven by processes like tectonic compression, sediment loading, mineral transformation, and heat flow. The latter is the focus of this contribution, which deals with the flow in basalt layers at the floor of the Pacific Ocean.

The study area is located $1700 \mathrm{~km}$ southwest of Manzanillo, Mexico in the equatorial northeast Pacific Ocean. The depth of the ocean ranges between 1460 and $4680 \mathrm{~m}$ (Kuhn et al., 2017) and the seabed is formed by basaltic crust, which is draped by a sediment cover of up to $100 \mathrm{~m}$ thickness. Locally, the crust protrudes through the sediment layer in the form of seamounts and N-S oriented ridges, which are about $100-300 \mathrm{~m}$ high, a few kilometers wide, and $10 \mathrm{~s}$ of kilometers long. The seamounts are extinct submarine volcanoes, which rise a few hundred to almost $3000 \mathrm{~m}$ over the surrounding abyssal plains. The circulation of seawater though the basaltic crust has been confirmed previously by heat flow measurements, and pore-water geochemical profiles (Kuhn et al., 2017). The outcrops of the protruding seamounts and N-S ridges are entry and exit points for seawater. Similar flow 
systems have been described elsewhere and the phenomenon of seawater entering one seamount and exiting from another has been termed a hydrothermal siphon (Fisher, 2005).

Figure 1 shows a conceptual model of such a hydrothermal siphon. A net flow between two outcrops develops only when a potential difference exists between them. The hydrostatic pressure exerted by the overlying ocean water is assumed to be the same everywhere, so the flow can only be initiated by density differences that are caused by the crustal heat flux, which is around $0.1 \mathrm{~W} / \mathrm{m}^{2}$ for oceanic crust of the working area (Kuhn et al., 2017). The high permeability of the basalts aids in the formation of upwelling plumes of relatively warm and downwelling plumes of relatively cold groundwater. Because of their fine-grained nature, the sediments are much less permeable than the basalts and thus mass transport in them is diffusion-dominated.

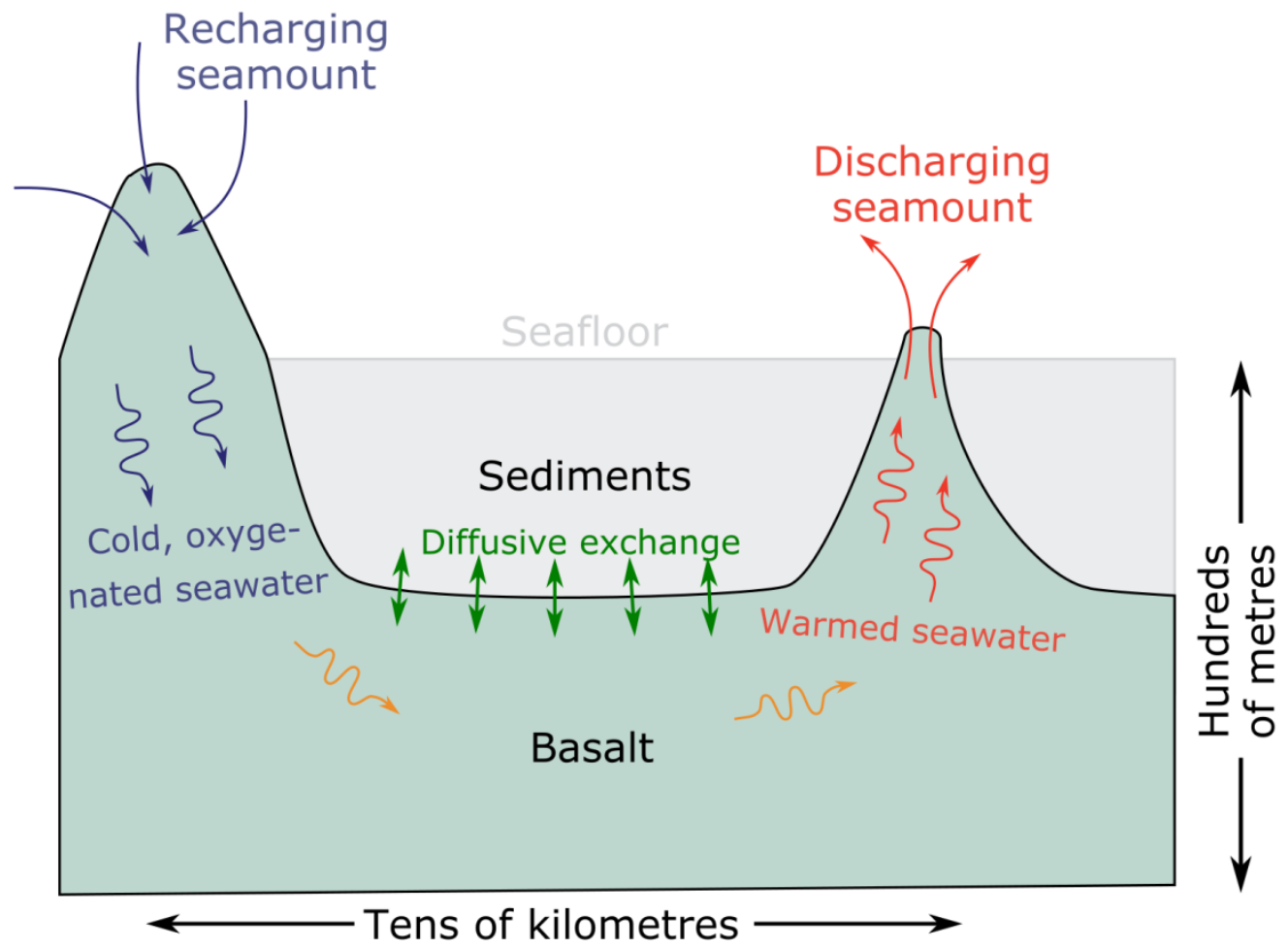

Figure 1. Conceptual model of the flow between two seamounts (modified fromFisher \& Wheat, 2010).

Little is known about hydrothermal siphons but they can be expected to play an important role in the cooling of the oceanic lithosphere, the solute budgets of the oceans (Fisher, 2005) and, potentially the formation of mineral resources such as manganese nodules. In the study area, for example, it has been found that dissolved oxygen is entrained by the seawater circulating through the basalt layer and enters the sediment layer from below by upward diffusion. To better understand the flow dynamics, as well as the heat and solute transport process, a numerical model was constructed that simulates the flow of seawater through a sediment-covered basaltic aquifer between a pair of basalt outcrops, which could either be seamounts or N-S ridges. 


\section{MODEL SETUP}

Figure 2 shows a schematic cross-section with the key features of the numerical model. The model was constructed using the software OpenGeoSys5 (Kolditz et al., 2012), which solves the system of equations for coupled fluid flow and heat transport in an iterative coupling scheme. The model domain as a vertical cross-section had a width of $10 \mathrm{~km}$ and the basalt layer beneath the sediment was $500 \mathrm{~m}$ thick. The thickness of the sediment layer was varied between 10 and $100 \mathrm{~m}$ and the height of the seamounts, which equaled the thickness of the sediment layer, was varied accordingly. The width of the outcrops was $200 \mathrm{~m}$.

The pressure at the seafloor was set to $\mathrm{P}_{0}=4 \times 10^{7} \mathrm{~Pa}$ (400 bar), and the temperature to $\mathrm{T}_{0}=$ $1.48{ }^{\circ} \mathrm{C}$, based on measurements. The temperature at the right outcrop was not specified though and was left to be calculated by the model instead. This allowed for the development of a pressure difference between the two basalt outcrops. A subsurface heat flux of $q_{h} 0.1$ $\mathrm{W} / \mathrm{m}^{2}$ was assumed along the bottom boundary of the model. The pressure and viscosity of water thus varied as a function of temperature. Other model parameters are shown in Figure 2. Initial runs were conducted to test the effect of grid discretization and time stepping on the simulation results. The mesh of the model with a sediment thickness of $100 \mathrm{~m}$ had 60,061 nodes and 60,000 elements, and tie time step used was $10^{9} \mathrm{~s}$.

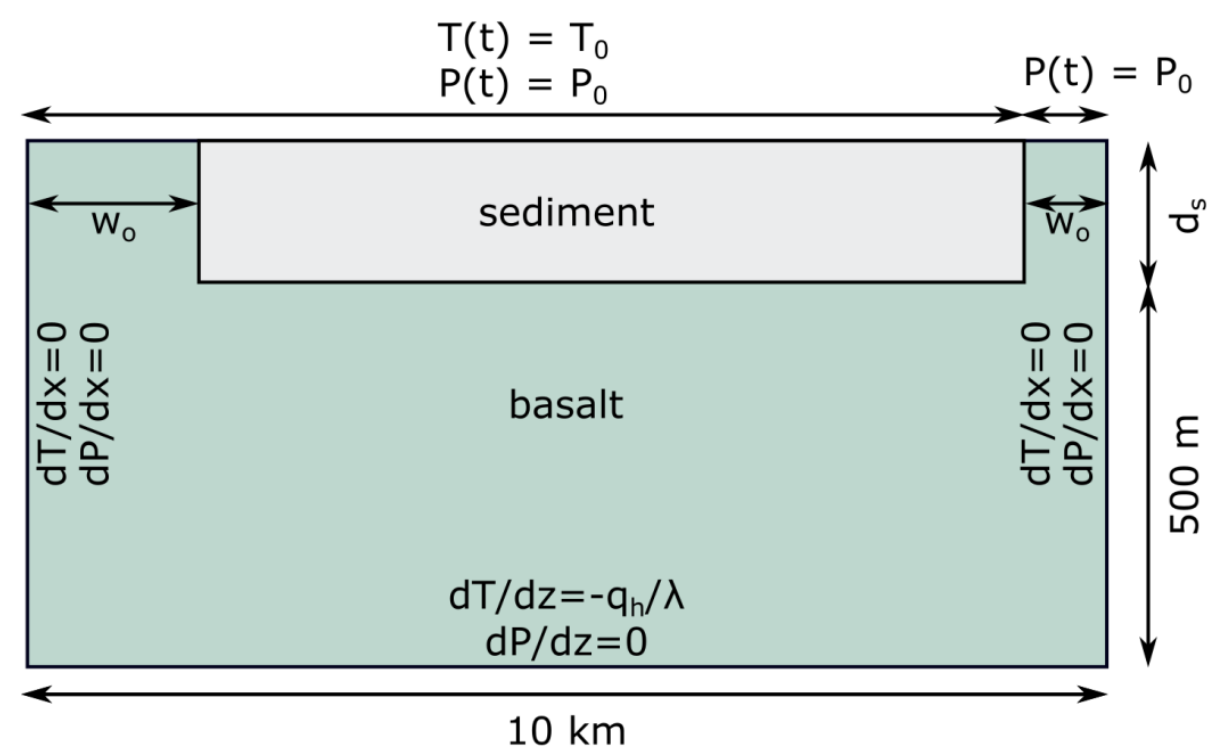

Figure 2. Cross-section showing the geometry of the model domain, lithological units and boundary conditions for temperature $T$ and pressure $P . w_{o}$ is the width of the outcrop, which was $200 \mathrm{~m}$ for the case presented here but varied and could be different between left and right for asymmetrical models. $d_{s}$ was the sediment thickness, i.e. 100 $m$ for the case presented here. Initial conditions were set to a constant temperature $T=$ $1.48{ }^{\circ} \mathrm{C}$ and a hydrostatic pressure distribution. $q_{h}$ is the crustal heat flux $\left(0.1 \mathrm{~W} / \mathrm{m}^{2}\right)$ and $\lambda$ is the thermal conductivity.

\section{RESULTS}

Figure 3 shows the temperature distribution after about 30,000 years for the model with a sediment thickness of $100 \mathrm{~m}$. The corresponding flow field is shown in Figure 4. These results clearly show that the system is unstable and that a convective flow system developed which is driven by the bottom heat flux. 


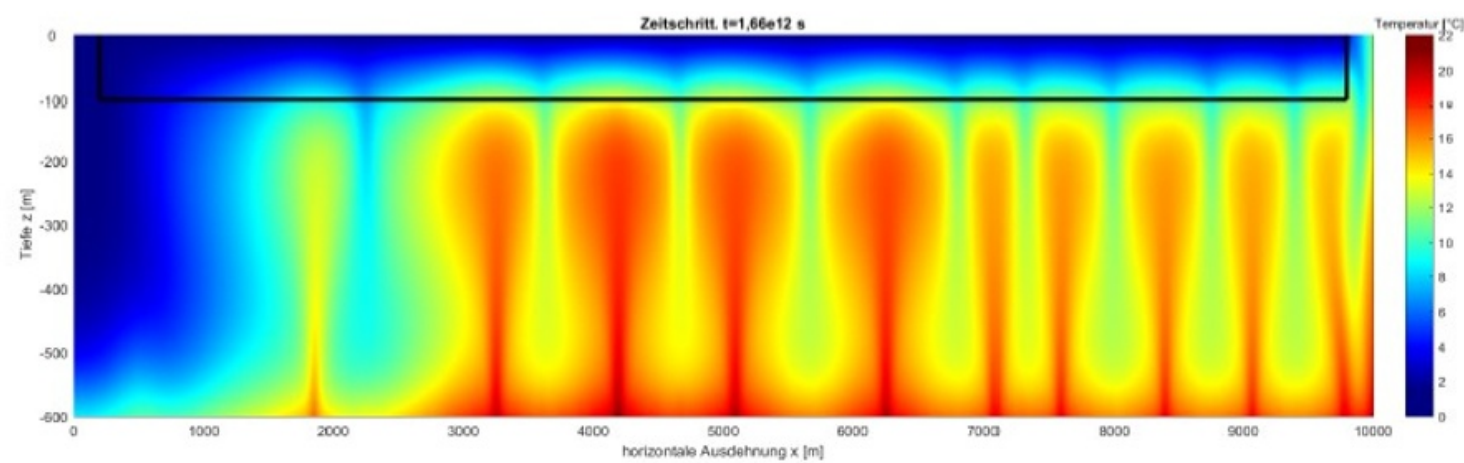

Figure 3. Temperature distribution for the model with a sediment layer thickness of $100 \mathrm{~m}$ after $9.15 \times 10^{11} \mathrm{~s}(\sim 30,000 \mathrm{y})$. The sediment layer is indicated by a black line. The corresponding flow field is shown in Figure 4.
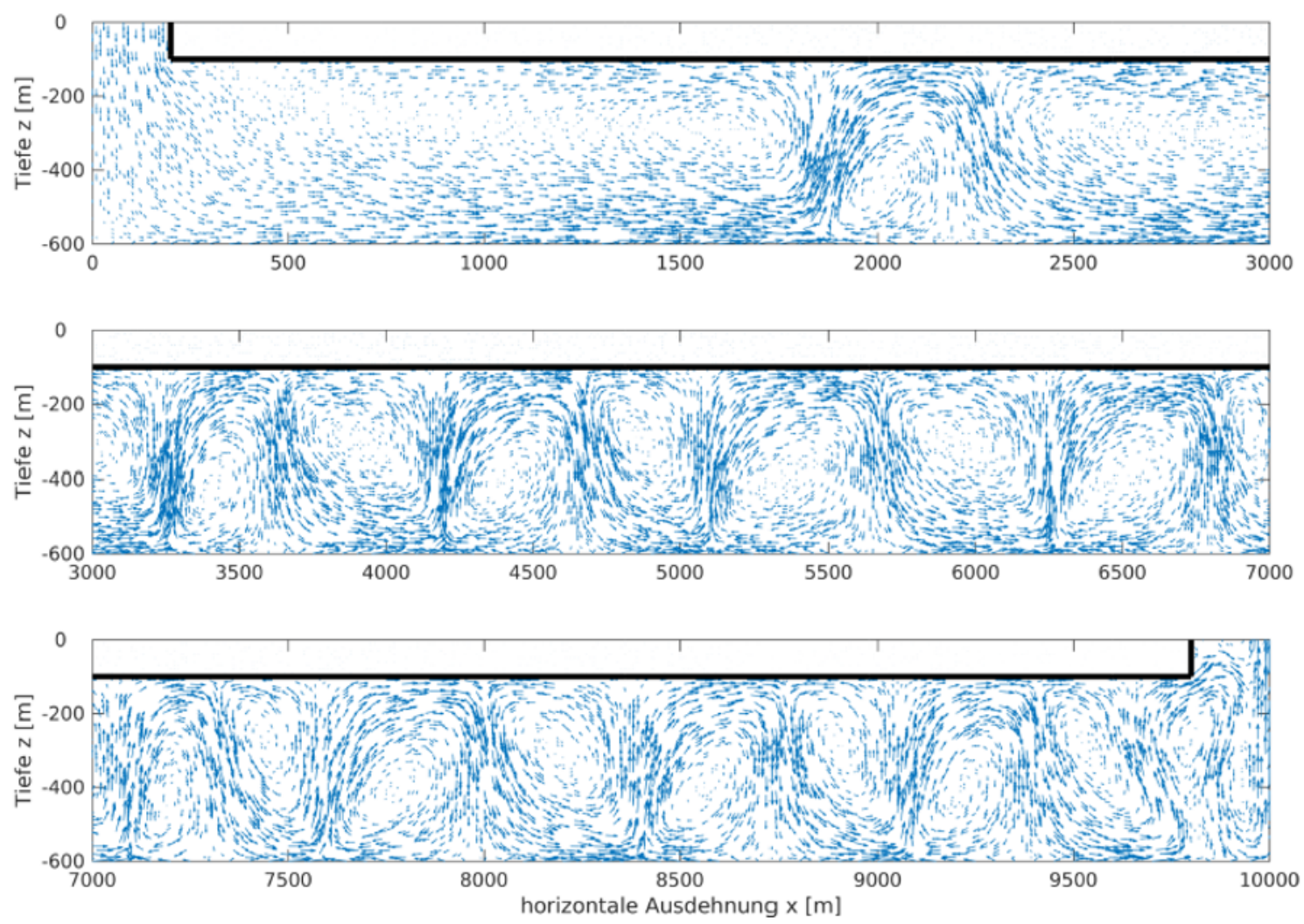

Figure 4. Vectors showing the magnitude and direction of the specific discharge $(q)$ field after $9.15 \times 10^{11} \mathrm{~s}(\approx \mathbf{3 0 , 0 0 0} \mathrm{y})$. Note that the model domain has been subdivided into three parts to improve the visibility of the vectors. The vectors were normalized with respect to the maximum specific discharge and the largest arrow represents a value of $q=5.7 \times 10^{-8} \mathrm{~m} / \mathrm{s}$.

The basalt outcrop on the left acts as the entry for seawater, whereas in the basalt outcrop on the right, there is both down- and upwelling of seawater (Figure 4). Mass balance calculations show that there is a net flow of seawater through the basalt from left to right. Running simulations with different sediment thicknesses showed that this net flow did not occur in the models with a sediment thickness $\leq 40 \mathrm{~m}$. Additional simulations (not shown here) indicate that the width of the basalt outcrops is another important parameter. 
Asymmetry of the outcrop width promotes the development of a siphon. Simulations yet to be conducted will also consider the distance between outcrops.

\section{DISCUSSION AND CONCLUSIONS}

The development of an unstable, free convection flow system was expected as the Rayleigh number $(R a)$ for the initial temperature profile is $R a=516$, which is much larger than the critical value of $R a_{c r}=17.65$. The model results indicate that, for the range of conditions considered in this study, a hydrothermal siphon does not develop when the sediment thickness $\leq 40 \mathrm{~m}$. Our preliminary interpretation of this observation is that this is because the transport of heat via conduction through the thinner sediment layers becomes more effective than via convection through the basalts. In models with a sediment thickness $\geq 60 \mathrm{~m}$, the thickness of the sediment layer prevented this, and thus a lateral flow component develops that conveys the energy out of the system. These modelling results provide support for the inferred circulation of seawater through the crustal basalt in the study area, as was suggested by Kuhn et al. (2017) based on heat flow and pore water concentration data. It is clear that pore waters beneath the ocean flow need not be stagnant but that there can be conditions where vigorous flow develops, provided that the permeability and heat flux are high enough. Hydrothermal siphons develop under favorable conditions, which include a heat flux high enough to cause potential differences, a thick sediment layer, and asymmetric basalt outcrops widths. The circulation of seawater through the basaltic crust does not only lead to its eventual cooling but also to a decrease of its permeability due to hydration reactions of the basaltic minerals, which lead to a decrease of porosity. Moreover, such hydration reactions may also lead to the mobilization of elements into solution and their transport back into the ocean. Considering the wide-spread existence of this type of off-axis ventilation, the neteffect of the return flow of mobilized elements on element fluxes and oceanic budgets may be very large.

\section{REFERENCES}

Fisher A.T. 2005. Marine hydrogeology: recent accomplishments and future opportunities. Hydrogeology Journal 13: 69-97.

Fisher A.T. and C.G. Wheat 2010. Seamounts as Conduits for Massive Fluid, Heat, and Solute Fluxes on Ridge Flanks. Oceanography 23: 74 - 87.

Kolditz, O., S. Bauer, L. Bilke, N. Böttcher, J.O. Delfs, T. Fischer, U.J. Görke, T. Kalbacher, G. Kosakowski, C.I. McDermott, C.H. Park, F. Radu, K. Rink, H. Shao, H.B. Shao, F. Sun, Y.Y. Sun, A.K. Singh, J. Taron, M. Walther, W. Wang, N. Watanabe, Y. Wu, M. Xie, W. Xu, B. Zehner 2012. OpenGeoSys: an open-source initiative for numerical simulation of thermo-hydromechanical/chemical (THM/C) processes in porous media. Environmental Earth Sciences 67: 589599.

Kuhn T., G.J.M. Versteegh, H. Villinger, I. Dohrmann, C. Heller, A. Koschinsky, N. Kaul, S. Ritter, A.V. Wegorzewski and S. Kasten 2017. Widespread seawater circulation in 18-22 Ma oceanic crust: Impact on heat flow and sediment geochemistry. Geology 45: 799-802.

Moore W.S. 2010. The Effect of Submarine Groundwater Discharge on the Ocean. Annual Review of Marine Science 2: 59-88.

Contact Information: Vincent Post, Federal Institute for Geosciences and Natural Resources (BGR), Stilleweg 2, 30655 Hannover, Germany, Phone: +49-511-6432393, Email:

vincent.post@bgr.de 